\title{
O Cluster Agroalimentar da Região Metropolitana de Londrina
}

\section{The Agribusiness Cluster of the Metropolitan Area of Londrina}

\author{
Márcia Regina Gabardo da Camara ${ }^{1}$; Paulo V. Sendin²; \\ José Carlos Dalmas ${ }^{3}$; Camila Perri Pinto ${ }^{4}$; Luiz Gustavo A. de Souza ${ }^{5}$
}

\section{Resumo}

O artigo analisa o cluster agroalimentar da região metropolitana de Londrina. Os principais produtos das cadeias produtivas inseridas neste conjunto são: milho, soja, trigo, café, arroz, algodão, feijão, uva, leite, cana e laranja.. Os procedimentos metodológicos adotados envolvem a caracterização da pesquisa de campo realizada pela ADETEC em 2002 para identificar as estratégias tecnológicas das empresas no que refere a produto e processo do setor agroalimentar das empresas. 29 empresas foram entrevistadas por conveniência. A classificação do tamanho das empresas foi feita pelo faturamento e números de empregados das firmas. O questionário da ADETEC tem 13 grupos de questões de caráter quantitativo e qualitativo. Realizou-se a análise fatorial para identificar a existência de diferentes padrões comportamentais e foram identificados 4 clusters de empresas. , segundo as estratégias adotadas por de micro/pequenas e médias/grandes empresas. Entre os principais resultados da pesquisa destacam-se o grau de cooperação técnico- científica de $38 \%$ a cooperação com instituições de pesquisa, para melhoramento do produto, pode ser observado que maior parte das empresas não possui este tipo de atividade, porém o número de empresas que possuem é significativo. Também foi possível identificar estatisticamente a diferença de estratégias de grandes/médias e pequenas empresas. Os resultados permitem à ADETEC formular políticas específicas para grandes/médias e para pequenas e microempresas do cluster agroalimentar da região metropolitana de Londrina.

Palavras-chave: Cluster. Agroalimentar. Londrina. Inovação.

\footnotetext{
${ }^{1}$ Doutora - Professora do Departamento de Economia - e-mail mgabardo@sercomtel.com.br

${ }^{2}$ Agrônomo - ADETEC e-mail sendin@adetec.org.br

${ }^{3}$ Doutor - Professor do Departamento de Matemática Aplicada - e-mail dalmas@uel.br

${ }^{4}$ Economista graduada na Universidade Estadual de Londrina

${ }^{5}$ Graduando de Economia -UEL .Bolsista PIBIC CNPq e-mail: luizgustavosouza@uol.com.br
} 


\begin{abstract}
The article analyzes the agribusiness cluster of the metropolitan area of Londrina. The main products of the productive chains inserted in this healthy group: corn, soy, wheat, coffee, rice, cotton, bean, grape, milk, cane and orange.. The adopted methodological procedures involve the characterization of the field research accomplished by ADETEC in 2002 to identify the technological strategies of the companies in what refers to product and process of the agribusiness section of the companies. 29 companies were interviewed by convenience. The classification of the size of the companies was made by the revenue and numbers of employees of the firms. The questionnaire of ADETEC has 13 groups of subjects of quantitative and qualitative character. Factorial analysis was used to identify the existence of different behoaviour patterns and they were identified 4 clusters of companies., according to strategies adopted by smalls, medium and big companies. Among the main results of the research they stand out the technical cooperation degree - scientific of $38 \%$ the cooperation with research institutions, for improvement of the product, it can be observed that larger part of the companies doesn't possess this activity type, however the number of companies that possess is significant. It was also possible to identify statistically the difference between big/medium strategies and small companies. The results allow to ADETEC to formulate specific politics for big/medium and for small businesses of the agribusiness cluster of the metropolitan area of Londrina.
\end{abstract}

Key words: Cluster. Agribusiness. Londrina. Innovation.

\section{Introdução}

Nas últimas décadas o processo de globalização da economia se intensificou e as inovações tecnológicas têm sido o veículo de mudanças, agilizando o processo de mutação da sociedade. Esta nova fase tem sido caracterizada como a Era do Conhecimento, na qual os ativos físicos, como instalações ou máquinas, perderam importância para os ativos intelectuais.

No modelo atual o primordial não é apenas ter acesso à informação, ou possuir um conjunto específico de habilidades, mas sim ter capacidade para adquirir permanentemente novas habilidades e conhecimentos, de forma a viabilizar o desenvolvimento de inovações que assegurem a manutenção ou ampliação da competitividade.

É nesse contexto que surge o conceito de "clusters", que consiste em aglomerações industriais dentro de uma área geograficamente delimitada, onde existe uma interação entre as empresas de um determinado setor econômico e entre elas e suas cadeias produtivas com o objetivo de assegurar um adequado nível de cooperação mútua que leve a vantagens competitivas no mercado globalizado.
$\mathrm{O}$ artigo discute a aglomeração de empresas agroalimentares na região metropolitana de Londrina que, para efeito deste estudo compreende os municípios de Apucarana, Arapongas, Rolândia, Cambé, Londrina, Ibiporã, Jataizinho, Uraí e Cornélio Procópio (eixo Apucarana-Londrina-Cornélio Procópio). Serão abordados brevemente os conceitos de cluster no setor agroalimentar, alguns aspectos da questão da inovação na teoria econômica, dandose também uma visão geral do setor agroalimentar no Estado do Paraná, de forma a contextualizar a região focalizada. Posteriormente serão apresentados os resultados de um levantamento preliminar realizado junto a um conjunto de 29 empresas desse setor, localizadas na região metropolitana de Londrina. A análise de suas características permite, enquanto estudo exploratório avaliar o perfil setorial e dentro das limitações impostas pelas dimensões e representatividade da amostra, caracterizar o cluster industrial agroalimentar da região metropolitana e sugerir políticas para incrementar a competitividade das empresas locais e desenvolver a região.

O enfoque de análise regional com base na teoria de clusters não é muito antigo e parte de um novo contexto mundial em que essa abordagem busca 
analisar as contribuições teóricas que envolvem a concentração geográfica das atividades produtivas e o relacionamento sistemático entre as empresas, governo e instituições não-governamentais. (IGLIORI, 2001)

Estas concentrações espaciais de firmas são independentes, as empresas trocam informações e cooperam entre si, além de partilhar coletivamente tanto de oportunidades quantos de ameaças, gerando novos conhecimentos e concorrência inovadora. Segundo Porter (1998), os clusters se caracterizam por grupos de firmas em indústrias correlatas e instituições especializadas que estão interligadas e presentes em uma determinada localização, e envolvem ligações verticais (compradores / fornecedores) e horizontais (clientes comuns, tecnologia, canais de comércio).

Há vários fatores que levam a aglomeração de determinadas indústrias em um determinado espaço geográfico( LASTRES; CASSIOLATO, 2003):

A existência de uma diversidade de recursos humanos com vários níveis de qualificação e competências profissionais; e de instituições de formação que permitem renovar os empregados;

- Condições de infra-estrutura para competir em determinado setor;

- Acumulação de atividades complementares (processamento da informação, entretenimento, saúde, serviços financeiros);

- Existência de canais formais e informais de difusão das inovações de base tecnológica ou organizacional.

Os efeitos dos clusters sobre as políticas de inovação são bastante significativos, pois as aglomerações exigem contínua capacidade de gerar e introduzir mudanças nos sistemas produtivos buscando o aumento da competitividade(LASTRES; CASSIOLATO, 2003; LINS, 2000). Além disso, a política de inovação busca fortalecer a dinâmica de cooperação/competição das empresas do cluster, bem como a ascensão de cada uma delas. O objetivo geral das políticas de inovação baseadas em cluster segundo o Programa Integrado de Apoio à Inovação (PROINOV) seria a remoção de falhas de mercado e falhas sistêmicas que impedem a plena exploração da dinâmica dos clusters para a competitividade e a inovação (...Os) tipos de falhas são: insuficiência ou ineficácia na oferta de bens público; falhas de coordenação entre os atores presentes; e a insuficiência na conexão às redes mundiais (PROGRAMA INTEGRADO DE APOIO À INOVAÇÃO, 2002a, p.3).

Partindo dessas definições gerais, distinguem-se agora as tipologias de cluster em termos de políticas de inovação feitas pelo Programa Integrado de Apoio à Inovação (2002b; 2002c): o micro cluster, o cluster industrial, o cluster regional e o mega cluster. O"Micro Cluster": é um conjunto geograficamente próximo de empresas interrelacionadas e de instituições associadas, atuando num campo particular de atividade (concorrem e cooperam entre si). O Cluster Industrial": é um conjunto de empresas inter-relacionadas, de fornecedores especializados, de prestadores de serviço, de empresas pertencentes a indústrias relacionadas e de instituições associadas que desenvolvem sua atividade em campos diferentes, recorrendo a tecnologias distintas mas complementares, e que pelas inovações que umas geram se concretizam em benefícios para as outras. O" Cluster Regional": é no essencial um "cluster industrial" cujas articulações principais funcionam no interior de um dado espaço regional, podendo essas articulações repetir-se total ou parcialmente noutras regiões do mesmo país. Por fim, o Mega Cluster": é um conjunto de atividades distintas, mas cujo bens ou serviços satisfazem a procura de uma mesma grande área funcional da procura final.

Portanto é possível observar os grandes ganhos que as empresas podem obter cooperando entre si, ao se instalarem - de forma natural ou a partir de políticas governamentais e privadas - em determinada região em clusters, pois elas melhoram não só a própria competitividade, como também aumentam o poder de concorrência da economia regional em geral, 
facilitando a inserção das empresas em mercados extra-regionais e mesmo internacionais(LEMOS, 2001, SUZIGAN, 2001).

As micro, pequenas e médias empresas são os tipos de firma que podem tirar um maior proveito de sua vinculação a um cluster pois, em geral, têm limitado poder de negociação junto aos fornecedores (compra de insumos e equipamentos, empréstimo junto a bancos comerciais, entre outros) devido à sua pequena escala de produção, além de enfrentarem grandes dificuldades para a introdução de inovações em seus produtos e processo, o que limita a criação de vantagens competitivas dentro do mercado, restringindo-se dessa forma sua presença na economia globalizada, onde a contínua diversificação é obrigatória para a concorrência com outras firmas (LEMOS, 2001). Para superar essa situação, segundo United Nations Industrial Development Organization (UNIDO), a cooperação entre as PMEs é a solução para as dificuldades que encontram:

Inter-enterprise cooperation also enables SMEs to specialize in their core bussiness and give way to an external division of labour thus improving their efficiency in production. Joint work also encourages enterprises to learn from each other, exchange ideas and experience to improve product quality and take over more profitable market segments. (UNITED NATIONS INDUSTRIAL DEVELOPMENT ORGANIZATION, 2001,p.1)

Com isto, a localização da empresa se torna um elemento chave para sua competitividade, pois os vínculos estreitos entre clientes e fornecedores, clientes e outras instituições, ou ainda entre clientes e sistema local de C\&T, afetam a vantagem competitiva da firma. Segundo Cunha, Oliveira e Cunha (2003, p.3), pequenas e médias empresas procuram se localizar "em regiões e locais que possibilitam desenvolver uma diversidade de relações sociais, baseados na complementaridade, na interdependência e cooperação".

Outro elemento chave na abordagem de cluster é o papel das instituições governamentais que devem ter uma intervenção ativa. Principalmente as universidades públicas para projetos de pesquisa em tecnologia. Porém para o desenvolvimento e fortalecimento dos arranjos produtivos o Estado e as instituições privadas devem ser harmônicos em suas relações para promover o desenvolvimento sustentável da área de atuação do cluster. Para potencializar o desenvolvimento dos arranjos produtivos, as ações devem ser orientadas a (CUNHA, 2002, p.9) :

- Buscar especialização e eficiência coletiva;

- Facilitar o acesso ao crédito para elevar a taxa de investimento das empresas já existentes e atrair novos investimento;

- Adensar a cadeia produtiva (insumos, bens de capital e serviços);

- Identificar nichos de mercado;

- Formar e capacitar recursos humanos;

- Fortalecer as relações com sistemas de inovação, mediante investimentos em pesquisa e desenvolvimento tecnológico;

- Garantir ambiente institucional que propicie a articulação entre as entidades empresariais e os governos estaduais e locais.

Portanto, a idéia geral da teoria de cluster seria as empresas de uma mesma cadeia econômica trabalharem em harmonia com os diversos agentes locais em uma mesma região, o que as tornam mais produtivas, inovadoras e competitivas, com mais possibilidade de atrair investimentos do que se atuassem isoladamente. Segundo Cassiolato, Lastres e Vargas (2003), as novas políticas industriais visam a proximidade geográfica das PME (Pequena, Média empresa) que torna de extrema importância a busca de competitividade nacional e esta interação é dificilmente conseguida pelas empresas sem um apoio governamental. Os autores apontam que a característica especifica de certa região é o que determina o desenvolvimento produtivo local da região. As especificidades do ambiente sócioeconômico dos países periféricos são fatores determinantes da conformação do desenvolvimento de sistemas produtivos locais . 


\section{Metodologia}

O levantamento dos dados preliminares que embasam as análises do setor agroalimentar da região de Londrina se deu no contexto do Programa Londrina Tecnópolis, executado pela Adetec - Associação do Desenvolvimento Tecnológico de Londrina e Região. Segundo Sendin (2002), a entidade, uma organização do Terceiro Setor, tem como missão principal o incentivo ao desenvolvimento tecnológico e no contexto de suas atividades, ela desenvolve uma série de levantamentos através de um setor denominado Siap - Sistema de Informação e Apoio a Projetos. O arranjo local de massas, salgadinhos, moinho de trigo, sorvetes e café agroalimentar_é reconhecido pelo IPARDES (2003, p.50-52), no texto “ Arranjos Produtivos Locais e o Novo Padrão de Especialização Regional da Economia Paranaense na década de 90." Durante o ano de 2002, a ADETEC promoveu a aplicação de um questionário junto a 100 empresas da região em foco, sendo que 29 delas se classificaram como pertencentes ao setor agroalimentar. (ESTEVES, 2002)

A escolha das empresas partiu de um grande cadastro construído pelo Siap a partir de diversas fontes, sendo que, do total de empresas cadastradas (cerca de 4.200), 672 foram classificadas no setor agroalimentar. Embora a pretensão inicial do trabalho desenvolvido pela Adetec fosse de realizar entrevistas com cerca de 460 empresas (das quais perto de 160 seriam desse setor), contratempos institucionais impediram que se cumprisse essa meta no prazo pretendido, de foram que, no momento, só estão disponíveis 29 questionários devidamente preenchidos.

As características dessa amostra trazem algumas dificuldades para a análise estatística dos dados coletados, já que o tamanho da mesma é limitado e sua heterogeneidade elevada. Esta última característica deriva do fato de que as entrevistas realizadas não seguiram um padrão seqüencial determinado em termos de tamanho, localização ou sub-setor a que pertenciam as empresas, pois esperava-se contornar eventuais problemas amostrais com a disponibilidade de um grande número de questionários (160, nesse setor).
O questionário utilizado se compunha de 13 grupos de questões, era bastante extenso e exigia entre 40 a 60 minutos de entrevista, muitas vezes envolvendo mais de um respondente por empresa, devido à diversidade dos assuntos enfocados. De posse dessas informações utilizou o método de Ward para calcular a as distâncias Euclidianas e verificar se estatisticamente era possível identificar grupos de empresas estatisticamente diferenciados dentro da amostra, isto é, verificar diferenças no comportamento estratégico das empresas a partir das categorias : faturamento, número de empregados, política de estágio, existência de estágio, controle de qualidade (todas as empresas realizaram, logo a variável foi excluída da análise), existência de um departamento de informática e grau de informatização(número de equipamentos em funcionamento) e cooperação técnico-científica formalizada entre a empresa e universidades e/ou institutos de pesquisa. . O procedimento para a formação de clusters utiliza as medidas Euclidianas quadráticas para determinar as distâncias entre observações. Inicialmente, o algoritmo seleciona observações que são marcadamente distintas para serem "sementes" iniciais de clusters; a seguir, aloca uma observação (uma empresa) ao cluster com a menor distância entre a observação e o centróide do cluster. As "sementes" são então substituídas pelas médias dos clusters temporários e o processo é repetido até que não haja mais nenhuma mudança e todas as observações estejam alocadas ao cluster mais próximo, produzindo a composição dos elementos de cada cluster com características similares (AAKER; KUMAR; DAY, 1995 apud BERGAMASCO, 2003)

Por tratar-se de estudo exploratório sobre os determinantes da competitividade local, utiliza-se a análise fatorial para estudar a combinação de variáveis que, a partir da identificação de um grau relevante de comunalidade entre si, criariam novos fatores, os chamados fatores latentes ou construtos subjacentes às variáveis observacionais, e que explicariam determinado comportamento comum das empresas pesquisadas. $\mathrm{O}$ construto teórico aqui discutido refere-se à ação inovadora e seus 
determinantes em empresas agroalimentares da região metropolitana de Londrina. Segundo sua finalidade, a análise do fator comum pode ser exploratória ou confirmatória.

\section{Análise dos Resultados}

Como pano de fundo da análise dos dados do levantamento propriamente dito, será apresentada uma visão resumida da situação do agronegócio no Paraná. A economia paranaense vem sofrendo uma série de mudanças desde a década passada com a reciclagem de sua estrutura produtiva em diversos setores da economia, inclusive no setor alimentar, objeto da discussão.O crescimento do estado sempre foi alimentado pela intensa atividade agrícola, e continua a ser um setor de dinamismo da sua economia, principalmente no interior do estado. Assim, a melhora da competitividade deste complexo é muito importante.

Estudos, como o de Laurenti (2000), mostram o declínio da participação da agricultura na economia do estado paranaense. Esta tendência pode ser verificada na Tabela 1, que apresenta a queda do valor adicionado do agronegócio no estado do Paraná. A partir de 1989 observa-se um aumento da atividade do não-agronegócio (atividades industriais e atividades comerciais), chegando a representar quase 60\% em 1996. Já as atividades do agronegócio (atividades agrícolas, atividades agroindustriais e atividades comerciais ), como foi dito, apresentaram queda - em 1989 representaram mais de $50 \%$, e em 1996, sua participação chegou a aproximadamente $40 \%$.

Tabela 1 - Evolução do "Valor Adicionado" do Estado do Paraná. 1989-1996.

\begin{tabular}{ccc}
\hline Ano & Total Agronegócio (\%) & Total Não-Agronegócio (\%) \\
\hline 1989 & 49,55 & 50,45 \\
1990 & 45,88 & 54,12 \\
1991 & 44,57 & 55,43 \\
1992 & 44,22 & 55,78 \\
1993 & 42,95 & 57,05 \\
1994 & 41,53 & 58,47 \\
1995 & 40,32 & 59,68 \\
1996 & 40,05 & 59,95 \\
\hline
\end{tabular}

Fonte: Adaptado de Laurenti (2000, p.61)
Segundo Lourenço (2000, p.37), o estado procura se reestruturar, pois há a necessidade de “enfrentamento e superação dos entraves intrínsecos à manutenção e/ou expansão da cadeia produtiva e, de outro, a imposição de pleno aproveitamento das oportunidades abertas por um ambiente globalizados dos mercados [...]".

Embora os dados da Tabela 1 indiquem uma redução histórica da participação do Agronegócio no PIB paranaense (o que seria de esperar, face ao natural processo de urbanização do Brasil e do Paraná), não se dispõe de informações mais recentes utilizando a mesma metodologia para o Paraná; logo é muito provável que a proporção 40\% / 60\% verificada em estudos recentes sobre o agronegócios brasileiros se confirme, pois o setor agroalimentar exportador vem se destacando como principal suporte dos superávits da balança comercial brasileira.(FURTUOSO; BARROS; GUILHOTO, 1998; CANUTO; RABELO; SILVEIRA, 1997).

A região Norte do Paraná, ao contrário do sul do estado, é área de colonização mais recente, desenvolvendo-se a partir da década de 20, sendo que Londrina, especificamente, completa em 2004 seu septuagésimo aniversário, pois foi fundada, oficialmente, em 1934. A base econômica da região, até a meados da década de 70 do século passado foi a cafeicultura, mas diversas outras explorações agrícolas são regionalmente importantes, tais como soja, milho, trigo, algodão, feijão, uva, laranja, cana de açúcar, olericultura, avicultura, leite etc.

Londrina até a década de 60 tinha o setor primário como responsável pelo dinamismo da cidade. Após a década de 70 começam os esforços para a atração de indústrias para a cidade, devido ao êxodo rural que foi decorrente da intensa industrialização na agricultura. No setor industrial, a agroindústria se expande, com a instalação de grandes e modernas unidades, diversificação da produção e maior integração com a agricultura. Neste processo, as cooperativas de produtores desempenham importante papel, aprofundando a interdependência entre o 
crescimento agro-industrial e as modificações ocorridas na produção rural. Essa base agrícola e a histórica vocação regional contribuem para que diversas agroindústrias tenham se instalado na região, justificando a preocupação com a realização de um diagnóstico setorial.

O diagnóstico aqui apresentado, embora padecendo das limitações metodológicas já mencionadas, apresenta um razoável conjunto de informações que cuja análise poderá contribuir com importantes subsídios ao aperfeiçoamento e à continuidade da proposta da ADETEC, na medida em que a mesma tenha condições de ser retomada em futuro próximo.

A primeira observação a ser feita a respeito dos dados coletados é quanto à constituição da "amostra" em relação ao porte das empresas. Conforme pode ser visto no Gráfico 1, há uma desproporcional presença de médias e grandes empresas, o que, seguramente, não se repete na população como um todo.

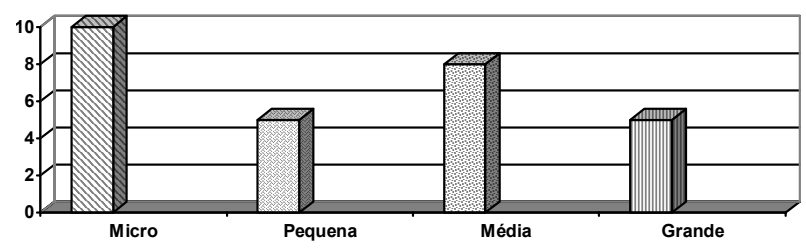

Gràfico 1- Porte de Empresas por Número de Funcionários Fonte: ADETEC / classificação segundo o Sebrae

Confirmando os dados sobre porte das empresas com base no número de empregados, as informações coletadas a respeito do faturamento das mesmas demonstram, conforme a Tabela 2, a presença de $62,1 \%$ de médias e grandes.

Tabela 2 - Porte das empresas do setor alimentar da RML segundo o faturamento

\begin{tabular}{lcr}
\hline & $\mathrm{N}^{\mathrm{o}}$ Empresas & Porcentagem \\
\hline Micro & 10 & 34,5 \\
Pequena & 1 & 3,4 \\
Média / Grande & 18 & 62,1 \\
Total & 29 & 100,0 \\
\hline
\end{tabular}

Fonte: pesquisa de campo ADETEC
A partir do porte da empresa em função do faturamento(PE) e das informações fornecidas pelas empresas no que tange a estágio(EST), política de estágio(PEST), força de trabalho(FTR), departamento de informática(DEINFO), número de computadores(NCOMP), gestão de qualidade (GQ) e cooperação técnica científica(CTCIENT), calculou-se através de do método de Ward as distâncias Euclidianas e verificou-se a existência de quatro grupo de empresas distintos. A análise de suas características permitirá a ADETEC sugerir políticas públicas para o desenvolvimento regional do cluster agroalimentar. Para a constituição dos clusters, informações completas de 12 empresas das 29 puderam ser aproveitadas - dezessete empresas forneceram dados incompletos e foram retiradas da análise fatorial. Verificou-se a existência de 4 agrupamentos diferentes de empresas (clusters), conforme apresentado pelo Gráfico 2 a seguir,a partir de características comuns, referentes à inovação.

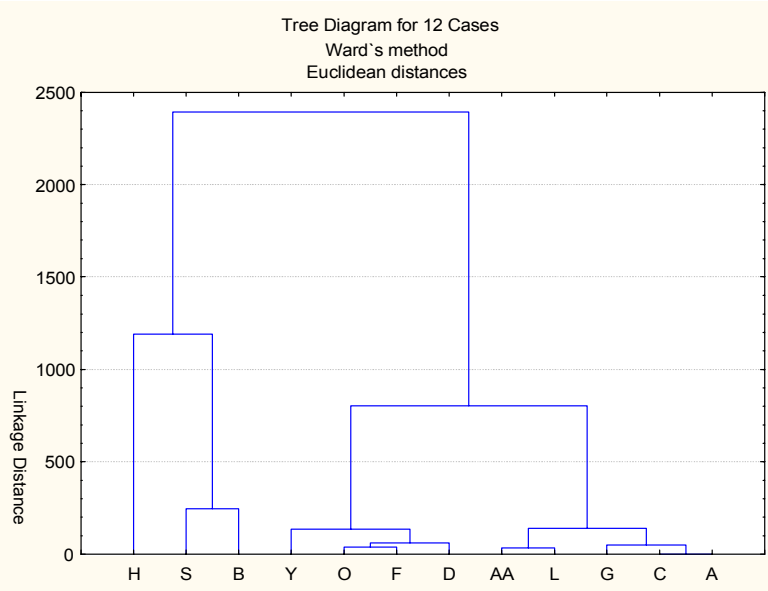

Gráfico 2 - Diagrama de Árvore para o Cluster Agroalimentar de Londrina.

Fonte: Dados ADETEC - pesquisa de campo

A despeito do viés da amostra, como revelado Gráfico 2 e confirmado pelo Gráfico 3, os três primeiros grupos de empresas se classificam em empresas grandes em faturamento, embora em termos de número de funcionários variem entre megaempresas(mais de 1500 empregados), grandes empresas(mais de 500 e menos de 1500 empregados) 
e empresas médias(mais de 250 e menos de 500 empregados).

O primeiro cluster é composto por uma megaempresa H, com 1600 empregados, com um departamento de informática ativo que utiliza 80 computadores, mas que não possui política de estágio, embora ofereça estágios a universitários, e verificase a ausência de cooperação técnico-científica com institutos de pesquisa locais e universidades da região. O segundo grupo é composto por 2 grandes empresas $(\mathrm{S}, \mathrm{B})$, onde há política de estágio ativa para interagir com as universidades, permitindo que os universitários sejam treinados 'on the job', permitindo a disseminação dos novos conhecimentos técnicos e administrativos de universitários na empresa. A interação é intensa com universidades e institutos de pesquisa pois se verificam inclusive projetos conjuntos e um departamento de informática com mais de 30 equipamentos. Este é um grupo inovador nas práticas regionais e que deve ser alvo de maiores estudos no futuro. Confirmado esse viés da "amostra" em relação ao tamanho das empresas, o mesmo deve estar sempre presente como referencial ao se proceder à análise e a discussão das características desse conjunto particular de empresas analisadas.

Embora não seja adequado realizar muitas extrapolações das análises para a população como um todo, acredita-se que os dois conjuntos restantes sejam representativos das firmas que se localizam na região, em virtude da existência de vantagens de aglomeração. Não é possível generalizar, pois a maior parte das variáveis a serem comentadas são, pela sua natureza, correlacionadas com o tamanho das empresas. O terceiro grupo é composto por cinco médias empresas (mais de 100 e menos de 500 empregados) - empresas Y, O, F,D, AA -, mas cujo faturamento as caracteriza como empresas grandes e revela o sucesso e o comportamento inovador. Neste grupo se verifica cooperação técnico-científica com universidades e uma política de informatização menos intensa das empresas.

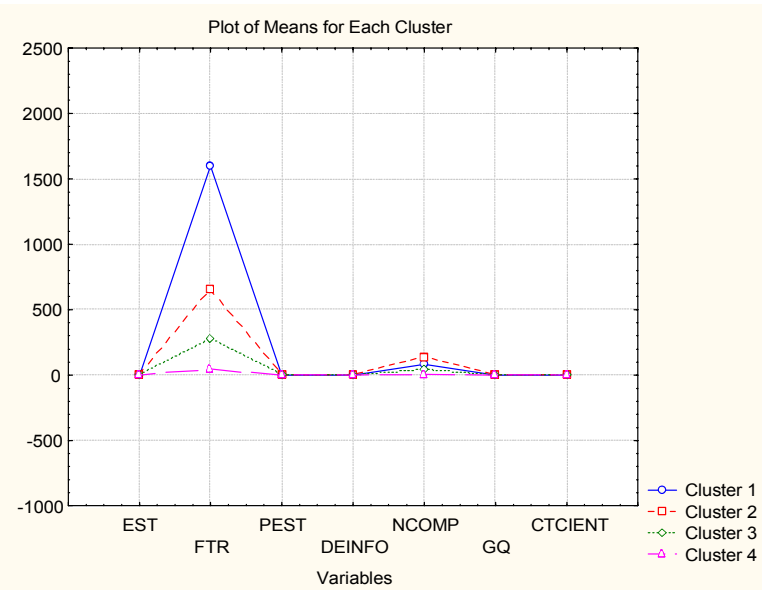

Gráfico 3 - O Cluster Agroalimentar na Região Metropolitana de Londrina

Fonte: Dados pesquisa de campo ADETEC.

Por fim, o último grupo é composto majoritariamente por microempresas que em sua maioria são pouco informatizadas e não adotam políticas de estágio e cooperação científica empresas A,C,G,L. Neste grupo, as quatro empresas salientaram a importância da política de estágio; os universitários trariam para a empresa conhecimentos técnicos e administrativos fundamentais para o crescimento e a competitividade empresarial. Dezessete empresas foram descartadas na formação de cluster em função do não fornecimento de todas as informações analisadas. Em resumo verificou-se que em 29 casos analisados, em 11 empresas há relatos de cooperação técnico-científica e que em 14 empresas a política de estágio permite não só treinamento "on the job", como a transferência de novas tecnologias administrativas e técnicas para as empresas.

O Gráfico 4 revela apresenta os 15 principais produtos e/ou linhas de atividades onde atuam as empresas pesquisadas. Assim, a moagem de trigo aparece com $17,2 \%$, que somados aos três principais produtos seguintes (fabricação de salgadinhos, sorvetes e café) representam quase $55 \%$ dos 29 elementos da amostra, revelando concentração de atividades. É importante destacar, que nesta análise preliminar, não está sendo levado em conta o porte 
dessas empresas, o que limita a possibilidade de se inferir sobre a prevalência econômica desses setores na estrutura produtiva regional.

No caso específico do setor de sorvetes, estudo sobre especialização de atividades, realizado pelo Sebrae do estado de São Paulo (SEBRAE, 2002) coloca Londrina como um dos principais núcleos produtores desse alimento, com 53 estabelecimentos, o que referenda os dados obtidos no levantamento realizado pela ADETEC.

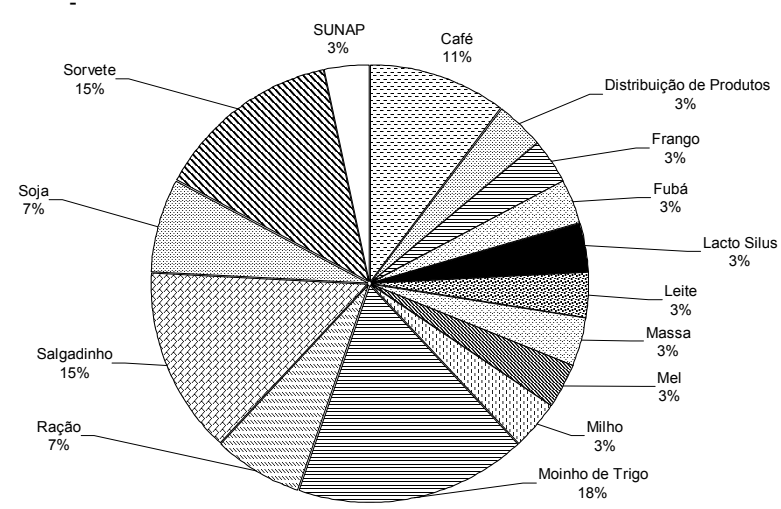

GRÀFICO 4 - Distribuição das empresas, segundo aréas de atuação ou produção

Fonte: Pesquisa de campo ADETEC. Total de empresas na amostra -29 firmas.

No que se refere ao tipo de atividade desenvolvida pelas empresas amostradas, ocorre uma óbvia o preponderância das que fabricam produtos para venda direta no mercado, com mais de $80 \%$ delas nessa categoria, conforme se pode observar no Gráfico 5. Tendo em vista que as possibilidades de classificação nesta questão não são mutuamente exclusivas, outras atividades também aparecem com relativa importância, tais como o desenvolvimento e a embalagem de produtos para outras empresas, ambas com uma presença de pouco mais de $40 \%$. Finalmente, a produção de matéria prima ou o fornecimento de serviços para outras empresas já são tipos de atividades menos freqüentes, ocorrendo em cerca de $20 \%$ dos entrevistados.
Gráfico 5 - Atividades que as organizações desenvolvem Fonte: pesquisa de campo ADETEC. As empresas podem escolher mais de uma opção.

Uma variável importante a ser analisada visando a definição de políticas de apoio ao setor agroalimentar da região é o destino da produção da produção, ou seja, quais os mercados preferenciais focados por essas empresas. A Tabela 4 apresenta o destino das vendas, classificando-as, de forma não mutuamente exclusiva, segundo 5 tipos de mercados.

Tabela 4 - Destino das vendas dos produtos

\begin{tabular}{|c|c|c|}
\hline Destino & $\mathrm{N}^{\circ}$ Empresas & $\%$ \\
\hline Toeal & 6 & 20,7 \\
\hline 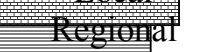 & 4 & 13,8 \\
\hline 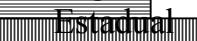 & 9 & 31,0 \\
\hline Nacionall & 19 & 65,5 \\
\hline Intermaeiona & 6 & 20,7 \\
\hline
\end{tabular}

Talvez em função do viés relativo da amostra em relação a empresas médias e grandes, a natural expectativa de uma concentração no mercado local e regional não se verifica plenamente. Observa-se, na citada Tabela 4, que mais de $65 \%$ das empresas entrevistadas atuam a nível nacional e que existe uma significativa percentagem (acima de 20\%) de participantes no mercado internacional. Mesmo considerando-se o viés da amostra em relação ao porte das empresas, o fato de uma significativa maioria atuar no mercado nacional permite inferir que existem boas possibilidades de que as mesmas venham a se capacitar a uma participação internacional. 
Essa visão da atuação geográfica das empresas da região leva à necessidade de se saber qual a percepção das mesmas em relação à identificação de seus concorrentes. A Tabela 4 revela que embora atuando com um enfoque nacional (65,5\%), a visualização da concorrência concentra-se no âmbito local/regional $(55,2 \%$ e $58,6 \%)$ e, em menor escala $(41,4 \%)$ no estadual. Pouco mais de um terço $(34,5 \%)$ das empresas assumem que seus concorrentes são de nível nacional e apenas 6,9\% (2 empresas) expressam preocupação com a presença de adversários internacionais. Tendo em vista essas respostas se referem à percepção dos entrevistados, é possível inferir que, ou de fato, a concorrência se dá entre os atores locais/regionais/estaduais (o que contraria as afirmações generalizadas sobre a globalização da economia) ou a percepção dos respondentes não reflete a realidade.

Tabela 4 - Localização dos principais concorrentes das empresas

Fonte: Levantamento ADETEC

Outra questão levantada pelo questionário e que é altamente dependente da percepção do respondente é a tentativa de se identificar quais os principais problemas enfrentados na produção. O Gráfico 6 apresenta o resultado desse questionamento, agrupando apenas aqueles que se apresentaram como mais relevantes, ou seja, com uma presença acima dos $10 \%$.

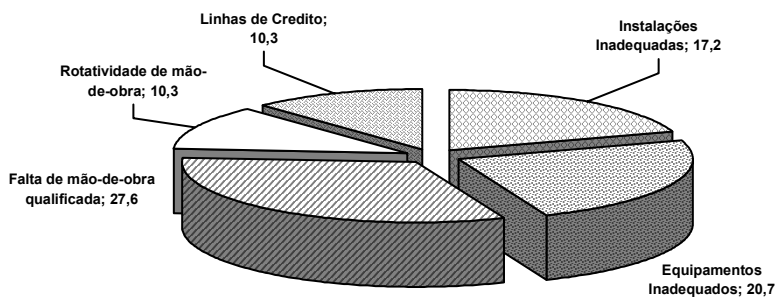

Gráfico 6 - Dificuldade técnicas encontradas na produção do produto $(\%)$

Fonte: Pesquisa de campo da ADETEC.

Segundo a percepção dos entrevistados, o principal problema enfrentado é o da falta de mão de obra qualificada $(27,6 \%)$, vindo a seguir a questão da disponibilidade de equipamentos inadequados (20,7\%). Além dos equipamentos, os empresários reclamam também da inadequação das instalações $(17,2 \%)$ e das dificuldades quanto a linhas de crédito $(10,3 \%)$ e do fator trabalho, agora em relação à rotatividade dos quadros de pessoal $(10,3 \%)$.

Outro aspecto importante para a análise do setor agroalimentar da região é o enfoque dado pelas

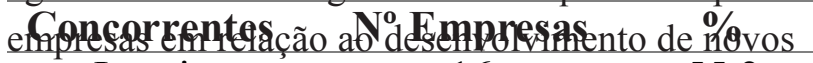
produtescajis seja, qual a poşura das mesnias $2 \mathrm{em}$ relachegionais Estaduais
mercados ${ }^{2}$ que atua. 12 Gráfico 41,4 são
Nacionais apresentados os. seis principais processos utiliządos pelas empresas, sendo que alguns deles apareeemconcomitantemente de forma que a soma das diferentes possibilidades supera os $100 \%$.

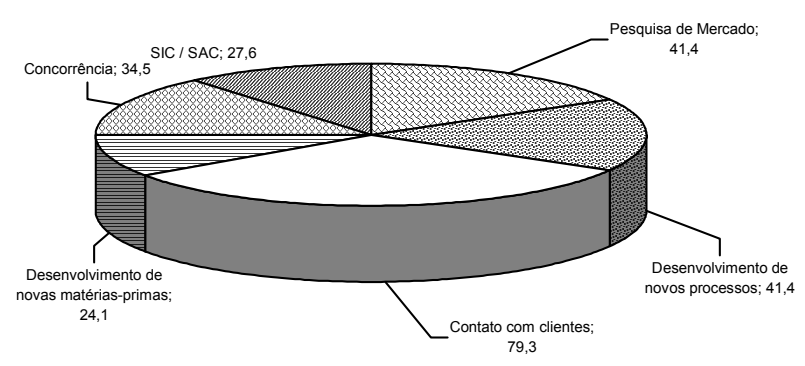

Gráfico 7 - Tipos de processos utilizados para geração de projetos de melhoramento / criação de novos produtos para o mercado (\%)

Fonte: Pesquisa de campo da ADETEC. 
O principal mecanismo de identificação de necessidades de inovações utilizado pelas empresas é o contato com o cliente que ocorre em $80 \%$ dos casos. A seguir, por ordem de importância, mas com pouco mais da metade $(41,4 \%)$ dessa primeira opção, encontram-se as pesquisas de mercado (que, de certa forma, é outro mecanismo de contato com os clientes) e o desenvolvimento de novos processos feitos por decisão da própria empresa. O quarto mecanismo citado na pesquisa foi o benchmarking junto aos concorrentes $(34,5 \%)$ e a participação dos clientes, agora na forma de atendimento a sistemas formais de SIC/SAC (Sistema de Informação ao Consumidor ou Sistema de Atendimento ao Consumidor) e, finalmente, outro processo interno de inovação, vinculado ao desenvolvimento de novas matérias primas que acabam por induzir a fabricação de inovações.

Bastante vinculado ao desenvolvimento de inovações situa-se a interação das empresas com entidades de Ensino e/ou Pesquisa. Os dados obtidos no levantamento realizado pela ADETEC indicam a ocorrência de 11 casos de interações formais das empresas entrevistadas com entidades de ensino/pesquisa, atingindo-se assim uma presença de 37, 9\% no total de 29 entrevistados. Mesmo levando-se em conta o viés da amostra quanto ao porte das empresas, essa inesperada ocorrência de um alto grau de interação do setor empresarial com o mundo de ciência e tecnologia sugere que as empresas da região estão começando a perceber a importância do conhecimento científico para a ampliação de seu nível de competitividade e de participação no mercado.

\section{Conclusões}

O complexo agroalimentar sempre se mostrou de extrema importância na história do Brasil, com a presença constante de um modelo primárioexportador, de a agricultura voltada para exportação. Com a crise de 29 e a II guerra mundial, o país começou o processo substituição de importação passando o mercado interno a ser valorizado.
A integração da indústria com a agricultura, historicamente presente desde a fase de implantação dos sistemas de produção de cana e açúcar no período colonial, passa no século XX a se tornar preponderante, intensificando-se nas décadas de 70 e 80, fenômeno esse presente em todo país e, até com maior ênfase, no Estado do Paraná. Mesmo considerando que a participação do complexo agroalimentar no PIB tenha decrescido, pela ampliação do vários outros ramos da indústria de transformação (têxteis, siderurgia, complexo automobilístico, aeronáutica etc), o chamado Agronegócio continua a ser uma atividade de excepcional dinamismo, contribuindo para a incorporação de novas áreas geográficas à economia nacional e para o crescente superávit comercial brasileiro.

No Paraná e, em especial, na região de Londrina, o setor tem se mostrado dinâmico e preocupado com a sua modernização. Novas análises setoriais do setor agroalimentar têm sido feitas e a que aqui foi apresentada contribui com um conjunto adicional de informações, embora padecendo de uma limitação de origem, face ao limitado tamanho da amostra e ao viés relativo à presença de uma alta proporção de empresas médias e grandes.

Mesmo considerando essas limitações, é válido concluir que o setor agroalimentar da região metropolitana de Londrina apresenta uma razoável propensão à inovação, demonstrada pela preocupação com a identificação de demandas dos clientes/ consumidores e pela significativa presença de interações formais entre as empresas da região e instituições de ensino e/ou pesquisa. Tal fenômeno é raramente identificado em outras regiões, principalmente quando afastadas dos grandes centros populacionais das capitais de estados.

O cluster agroalimentar da região apresenta condições de desenvolvimento bastante interessantes, face ao conjunto de ativos tecnológicos específicos disponíveis na região, onde se situam duas importantes entidades de pesquisa agropecuária 
(Iapar e Embrapa/Soja) e uma Universidade (Uel) com um significativo conjunto de cursos, grupos de pesquisa e pesquisadores nas áreas de conhecimento correlatas às Ciências Agrárias.

Essas condições, associadas à necessária organização do setor produtivo, de forma a que o cluster agroalimentar realmente se cristalize pela interação entre seus componentes, devem ser melhor estudadas no futuro, com o aprofundamento dos levantamentos que vêm sendo realizados pela ADETEC. Para tanto, recentemente foi estabelecida uma parceria entre a ADETEC e o Sebrae/Pr Londrina visando dar seqüência a este levantamento, agora com uma amostra de cerca de 150 empresas, o que permitirá o aprofundamento das análises aqui elaboradas e a obtenção de um diagnóstico mais apurado do setor agroalimentar da região metropolitana de Londrina.

A análise de cluster( conglomerado) permitiu identificar grupos com condutas diferentes e sinalizou a necessidade de um tratamento diferenciado para pequenas, médias e grandes empresas, na gestão e formalização de políticas de infra-estrutura tecnológica. Por outro lado, também evidenciou que uma parcela significativa das empresas segue à margem das transformações - dezessete empresas pequenas -, logo a disseminação de inovações em termos de boas práticas, novos processos e novos produtos não é homogênea e a transformação setorial e regional ocorre de forma assimétrica. A existência de empresas de grande e médio porte com elevada capacidade de inovação, adoção de políticas de estágio, treinamento de mão-de-obra, crescente uso da informática, crescente gestão de qualidade e cooperação técnica com institutos de pesquisa e universidades locais, confirma a heterogeneidade e sinaliza o potencial diferenciado das empresas, de um lado, requer políticas horizontais que permitam a crescente competitividade. Por outro lado, para o grupo de empresas médias e pequenas que estão à margem , a inserção da política de estágio e a informatização, incentivadas por políticas municipais e por linhas de crédito específicas para pequenas empresas, assim como a cooperação empresauniversidade na solução de problemas operacionais e financeiros e futuramente, tecnológicos e de qualidade poderiam incrementar o crescimento regional.

O surgimento do "cluster" agroalimentar de Londrina ocorreu de forma natural, a região tem apresentado vantagens competitivas em relação a outras regiões do estado do Paraná, devido ao seu solo fértil, clima ameno e desenvolvimento urbano recente. Mas o "cluster" está em processo de desenvolvimento, podendo até ser classificado como arranjo produtivo local, pois os elos entre firmas, fornecedores e mercado podem ser intensificados. A articulação inter- empresas, instituições de ensino e pesquisa e governo também poderia ser mais significativa, apesar da região dispor de todos os ativos necessários para a consolidação deste "cluster". Ele pode ser classificado como um "cluster" natural, pois as empresas estão instaladas na região devido ao fácil acesso a matérias - primas, mas não porque é um pólo inovador e tecnológico neste setor. Destaca-se neste contexto o papel da ADETEC na intensificação das atividades das organizações geradoras de inovações e articulações entre as empresas para que elas cooperem entre si. Também deve ser dado suporte às empresas agroalimentares para superar os estrangulamentos identificados no que tange à qualificação da mãode-obra, da adequação das ferramentas aos serviços e a intensificação do desenvolvimento de produtos, em sua maioria, orientado por clientes, com crescente utilização da cooperação com institutos de pesquisas, universidade e empresas e portanto incrementem a ação inovadora em diferentes prismas, incentivando o desenvolvimento regional. 


\section{Referências}

ASSOCIAÇÃO DO DESENVOLVIMENTO TECNOLÓGICO DE LONDRINA E REGIÃO. Dados $d a$ Pesquisa de Campo. Londrina, 2002.

BERGAMASCO, Fernando Lovel, Estudo da Competitividade das Empresas da Construção Civil de Londrina. 2003. Dissertação (Mestrado) - PPA/ UEM/UEL, Londrina, 2003.

CANUTO, Otaviano; RABELLO, Flávio M.; SILVEIRA, José M. Abertura e Grupos Econômicos na Indústria Brasileira. Revista Paranaense de Desenvolvimento, Curitiba, n.92, p 33-52, set.-dez. 1997.

CASSiOlAto, J.; LASTRES, H.; VARGAS, M. Cooperação e competitividade de MPME: uma proposta de instrumentos financeiros voltados a arranjos produtivos Locais. Disponível em: <www.iadb.org/ foromic>. Acesso em: 1 set. 2003

CUNHA, Sieglinde K.; OLIVEIRA, Maria Aparecida; CUNHA, João Carlos. Clusters: novo padrão de especialização da indústria paranaense na década de 90 . SEMEAD., 6., 2003. Anais... São Paulo: USP, 2003. Disponível em: <http://www.ead.fea.usp.br/Semead/ 6semead/PGT.htm>. Acesso em: 8 set. 2003.

CUNHA, Sieglinde K. da (Coord.). Mudança Estrutural no Padrão de Aglomeração Especial na Indústria Paranaense. Curitiba: IPARDES, 2002.

ESTEVES, P.C. et al. Sistema de Informação e Apoio a Projetos: A Experiência do Projeto Londrina Tecnópolis. In: CONGRESSO NACIONAL DAABIPTI, 2002, Curitiba. Anais... Curitiba: Associação Brasileira, 2002.

FURTUOSO, Maria Cristina O; BARROS, Geraldo S. C.; GUILHOTO, Joaquim J. M. O Produto Interno Bruto do Complexo Agroindustrial Brasileiro. Revista de Economia e Sociologia Rural, Brasília, v.36, n. 3, jul./set., 1998.

IGLIORI, Danilo C. Economia dos clusters industriais e desenvolvimento. São Paulo: Iglu, 2001.

IPARDES, Arranjos Produtivos Locais e o Novo Padrão de Especialização Regional da Economia Paranaense na década de 90. Curitiba: IPARDES, 2003.

LINS, Hoyêdo Nunes. Clusters industriais, competitividade e desenvolvimento regional: da experiência à necessidade de promoção. Estudos Econômicos, São Paulo, v.30, n.2, abr/jun. 2000.

LASTRES, H. M. M.; CASSIOLATO, J.E. Novas políticas na era do conhecimento: o foco em arranjos produtivos e inovativos locais. Parcerias estratégicas. Rio de Janeiro: UFRJ, 2003.
LAURENTI, Antonio C. Evolução Recente da Economia Paranaense e o Desenvolvimento Desigual do Agronegócio. In: IAPAR. Agronegócio do Paraná - perfil e caracterização das demandas das cadeias produtivas. Londrina, 2000. p. 51-72.

LEMOS, Cristina. Inovação em Arranjos e Sistemas de $M P M E$. In: Proposições de políticas para a promoção de sistemas produtivos locais de micro, pequenas e médias empresas. Rio de Janeiro: UFRJ, 2001.

LINS, Hoyêdo Nunes. Clusters industriais, competitividade e desenvolvimento regional: da experiência à necessidade de promoção. Estudos econômicos, São Paulo, v.30, n.2, abr/jun. 2000.

LOURENÇO, Gilmar M. Cenários do Agronegócio no Paraná: restrições e oportunidades. In: IAPAR. Agronegócio do Paraná - perfil e caracterização das demandas das cadeias produtivas. Londrina, 2000. p. 3750 .

PORTER, M. E. Clusters and the new economics of competition. Harvard Business Review, Boston, v.1, p.7790, nov/dec, 1998

PROGRAMA INTEGRADO DE APOIO À INOVAÇÃO (PROINOV). Clusters e política de inovação: II-Clusters: conceito, tipologia, exemplos europeus. Lisboa: Comunidade Econômica Européia, Presidência do Conselho de Ministros, 2002a.

PROGRAMA INTEGRADO DE APOIO À INOVAÇÃO. Clusters e Política de Inovação: III - Megaclusters: uma abordagem exploratória. Lisboa: Comunidade Econômica Européia, Presidência do Conselho de Ministros, 2002b.

PROGRAMA INTEGRADO DE APOIO À INOVAÇÃO. Clusters e Política de Inovação: V - Os clusters e as políticas de inovação. Lisboa:Comunidade Econômica Européia, Presidência do Conselho de Ministros, 2002c.

SEBRAE (SP). Subsídios para a identificação de clusters no Brasil: atividades da indústria. São Paulo, 2002.

SENDIN, Paulo V. O Papel do Terceiro Setor na Definição de Arranjos Locais de Inovação: O Caso da ADETEC. In: SIMPÓSIO DE GESTÃO DA INOVAÇÃO TECNOLÓGICA, 22., 2002, Salvador. Anais... Salvador, 2002.

SUZIGAN, W. Aglomerações Industriais como foco de políticas. Revista de Economia Política, São Paulo: v.21, n.3, jul./set., 2001.

UNITED NATIONS INDUSTRIAL DEVELOPMENT ORGANIZATION. Development of Clusters and Networks of SMEs. Vienna, 2001. 
